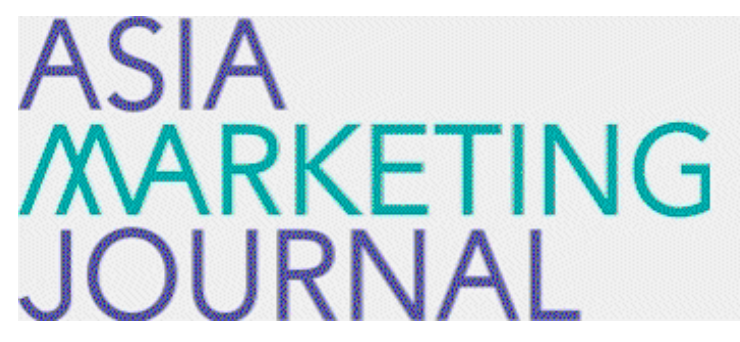

ASIA MARKETING JOURNAL

Volume 2 | Issue 2

Article 3

$6-1-2000$

\title{
시도이론에 관한 이론적 연구
}

Richard P . Bagozzi

Follow this and additional works at: https://amj.kma.re.kr/journal

Part of the Marketing Commons

\section{Recommended Citation}

Bagozzi, Richard P. (2000) "시도이론에 관한 이론적 연 구," Asia Marketing Journal: Vol. 2 : Iss. 2 , Article 3.

Available at: https://doi.org/10.53728/2765-6500.1038

This Article is brought to you for free and open access by Asia Marketing Journal. It has been accepted for inclusion in Asia Marketing Journal by an authorized editor of Asia Marketing Journal. 


\title{
시도이론에 관한 이론적 연구 \\ : 목표지향적 행동을 중심으로 ${ }^{*}$
}

\section{A Theoretical Investigation into the Theory of Trying}

\author{
이유재( 서울대학교 경영대학 부교수) \\ youj ae@snu. ac. kr
}

Ri char d P. Bagozzi ( Uni ver si ty of M chi gan 교수)

bagozzi @um ch.edu

많은 소비자 행동은 목표 지향적 행동으로 볼 수 있다. 이처럼 목표가 소비행동에서
차지하는 비중이 높다보니 최근 들어 목표자체에 대한 연구와, 목표의 추구와 성취에 있어
태도의 역할에 대한 연구에 상당한 관심이 집중되고 있다. 그런데 지금까지의 태도연구는
주로 이성적인 행동에 그 초점이 맞추어져 왔으며 그 대표적 모델은 Fi shbei n과 Aj zen의
이성적 행동이론이다. 이성적 행동이론이 소비행동을 설명하는데 많은 기여를 했으나
목표지향적 행동을 설명하는데는 어느 정도 한계가 있다고 지적된다. 이 논문에서는
이성적 행동과 목표지향적 행동과의 차이점들을 살펴보고 목표지향적 행동을 설명하는
새로운 연구모형으로서 시도이론을 소개하였다. 또한 시도이론에 대한 실증 분석의
결과들을 제시하고 있다.

* 논문접수:00.2 게재확정:00.6 


\section{1. 서 론}

많은 소비자 행동은 목표 지향적 행동으로 볼 수 있다. 목표지향적 행동( goal-directed behavi or) 은 내구재(예를 들어 재무관리 목적으로 한 컴퓨터의 구입), 비내구재 (사용하기 편하고 효과적인 세제의 구입), 서비스(체중조절을 위한 헬스클럽 가입), 아이디어나 사람 (자신에게 가장 도움이 될 후보를 위한 투표) 등에 이르기까지 다양한 분야에서 발견된다(Bagozzi \& Dhol aki a 2000). 또 예를 들어 병원약국에서 안전하고 효과적이며 값싼 약품을 찾는 활동에서처럼 조직구매에 있어서도 목표지향적 행동을 볼 수 있다. 이런 여러 활동들에 있어서 목표란 행동이 가져올 수 있는 특정 결과에 초점을 맞추고 있다. 즉 바라는 결과가 의사결정자의 마음에 들어오게 되면 목표가 되는 셈이다.

이처럼 목표가 소비행동에서 차지하는 비중이 높다보니 최근 들어 목표자체에 대한 연구와, 목표의 추구와 성취에 있어 태도의 역할에 대한 연구에 상당한 관심이 집중되고 있다. 그런데 지금까지의 태도연구는 주로 이성적인 행동에 그 초점이 맞추어져 왔으며 그 대표적 모델은 Fi shbein과 Ajzen의 이성적 행동이론(theory of reasoned action)이다 (임종원 외 3인, 1999; Aj zen and Fi shbei n 1980; Fi shbei $n$ and Aj zen 1975). 이성적 행동이론이 소비행동을 설명하는데 많은 기여를 했으나 목표지향적 행동을 설명하는데는 어느 정도 한계가 있다고 지적된다 Bagozzi and Dhol aki a 2000).

따라서 이 논문에서는 이성적 행동과 목표지향적 행동과의 차이점들을 살펴보고 목표지향적 행동을 설명하는 새로운 이론으로 제시되는 시도이론(Theory of Trying)을 소개하고자 한다. 또한 시도이론에 대한 실증 분석의 결과들을 제시한다.

우선 이성적 행동이론에 깔려 있는 주요 가정들은 살펴보면 다음과 같다 Fi shbei n and Aj zen 1975; Petty and Caci oppo 1986). 첫째, 개인이 행동을 하기 전에 그 행동의 결과를 고려하고 행동하겠다는 결정을 내리는 의식적이고 신중한 사고과정이 선행된다. 둘째, 일단 개인이 행동하려고 시도한다면, 능력제한이나, 자금부족, 상황조건, 무의식적 습관과 같은 어떠한 방해물도 그 행위의 수행을 막지 못한다.

한편 행위수행에 있어 방해물이 존재하는 행위들(예: 새 차의 구입, 최고 변호사의 고용, 금연)은 목표라고 부를 수 있다. 이러한 관점에서 본다면, 어떤 행동들을 목표라고 할 수 있는가? Aj zen(1985)은 아무리 하찮은 행동이라도 어떤 예기치 않은 사건을 당할 가능성이 있으므로 (예: 교통사고로 인한 음악회 불참) 거의 모든 행동들이 목표라고 주장한다. 그러나 Aj zen의 이런 주장에는 두 가지 문제점이 존재한다.

첫째, 그의 시각은 너무 포괄적이라서 전형적으로 상황적 방해를 받는 행위와 상황적 
방해를 받지 않는 행위들간의 의미있는 차이를 무시한다.

둘째, Aj zen(1985) 의 주장은 방해물에 대한 의사결정자의 인식이나 자각을 고려하고 있지 않다. 의사결정자들은 행위를 실천하거나 목표를 달성하려고 할 때 장애를 줄 수 있는 내 외적인 방해물에 대해 평가를 하게 된다. 만약 방해물이 있다고 생각한다면 행동이나 목표추구는 불확실한 것으로 여겨질 것이다.

이러한 점들을 고려해 볼 때 우리는 두 가지 종류의 목표지향적 행동을 정의할 수 있다. 바람직한 결과를 성취하는 데 필요한 행동인데 장애가 있는 것을 중간목표지향적 행동이라 하며, 목표자체로 추구되어지는 행동으로 장애가 있는 것을 결과목표지향적 행동이라 한다. 목표지향적 행동의 이러한 유형들에 대해 보다 자세히 살펴보기로 하자.

우리는 목표라는 용어를 개인이 그것을 수행하는데 방해물이 존재한다고 생각하는 행동이나 결과로 국한시켜 사용하기로 한다. 개인의 의사결정에 영향을 끼치는 것은 장애물의 존재유무에 대한 이러한 인식이지 실제의 존재여부 그 자체는 아니다 (Bagozzi, $\mathrm{Yi}$, \& Baungartner 1990). 따라서 방해물이 잠재적으로 존재할 가능성만으로도 개인이 행동수행이나 목표달성을 위해 시도하느냐가 영향을 받는다.

그러면 어떤 상황에서 하나의 행동이 중간 목표가 되는가?

첫 번째 경우는 공급의 부족이다. 예를 들어, H. O.T. 의 공연입장권을 구입하거나, 추석 명절 때 귀성 열차표를 예매하는 것이 목표가 될 것이다. 마찬가지로 무더운 한여름에 에어컨이나 선풍기가 부족하다면 이것들의 구매자체가 목표가 될 것이다.

두 번째 경우는 자원의 부족에 관계된다. 한 개인이 어떤 제품을 구매할 능력이 없을 때와 같은 경우에 해당한다. 예를 들어 사고자 하는 것이 아주 값비싼 주택이나 차일 경우 소비자는 지불할 능력이 문제가 된다.

세 번째 경우는, 불가능할 수도 있는 특정 시간 내에 행위를 완수하려고 시도하는 것과 관련된다. 예를 들어 하루만에 기말시험 공부를 벼락치기하는 것이 이에 해당된다. 여기서 사람들은 그런 행동에는 잠재적으로 장애가 있다는 것을 알고 있다. 따라서 기대하는 행동이 개인의 마음속에서 목표가 되는 것이다.

마지막으로, 의지력의 부족이나 무의식적인 습관 때문에 행동하려는 의식적 욕구가 방해받을 수 있는 상황들이 존재한다. 예를 들면 황진이의 유혹에 빠진 지족선사, 아이스크림의 유혹에 빠진 다이어트 수행자, 금연을 원하지만 실천하지 못하는 흡연자가 이에 해당된다. 어떤 이가 자신의 의지력이 약하고 오래된 습관이 자신의 계획에 영향을 끼칠 것을 알고 있다면, 그 사람은 장애물이 존재하는 그 행동을 목표로 간주하게 된다. 이상과 같이 최종목표를 추구하는데 필요한 행동들의 많은 경우가 그 수행시 장애요인이 존재하므로 중간 목표라고 할 수 있다.

중간목표뿐만 아니라 최종목표나 결과도 연구할 수 있다. 예를 들어 주식투자로 $20 \%$ 의 수익을 얻는 것이나 복권에 당첨되는 것이 그런 경우이다. 이런 목표지향적 행동들은 
이성적 행동이론과 같은 모형으로 설명할 수 없다. 왜냐하면 그 이론의 기본적 가정은 단순히 행동의도가 행동수행을 결정한다는 것인데, 목표지향적 행동의 경우에는 이런 가정이 적용되지 않기 때문이다. 예를 들어 복권에 당첨되려는 의도가 있다해서 복권에 당첨되는 것은 아니다. 그러므로 비록 이성적 행동이론이 투자회사를 선택하고, 여러 은행들에게 대출신청을 하고, 매주 10 장씩의 복권을 구입하는 것 등의 행동을 다룰 수는 있지만, 그러한 행동을 통해 추구하는 결과나 목표를 설명하는 데는 부적합하다. 즉 이성적 행동이론은 특정 결과들이 중요한 이유, 성공이나 실패가능성이 어느 정도인가와 같은 문제들에 대해서 설명하거나 이해하려 하지 않는다. 이 이론은 단순히 중요하게 여겨지는 결과들을 도출하고 이들의 시사점을 다룰 뿐이다. 하지만 그러한 결과목표들은 단순히 한가지 행위와 관련된 것이 아니라 다양한 행동들을 통해 추구될 수가 있다. 예를 들어, 미팅에서 만난 여학생에게 좋은 인상을 주기 위해(목표) 멋진 의상을 구입한다고(이성적 행동) 가정해보자. 하지만 다른 행동들도 이 목표를 달성하는 데 도움이 될 수가 있으며, 어쩌면 다른 행동들이 의상구입보다 훨씬 더 효과적일 수가 있다 (예: 장미꽃 한 다발을 선사한다는 것 등) .

Fi shbei n과 Aj zen의 이성적 행동이론을 목표연구에 적용하는 데는 여러 가지 어려움이 있다 (Sej wacz, Aj zen, Fi shbei n 1980). 예를 들어보자. 프로야구단 구단주가 다음 시즌에 자기 팀을 어떻게 우승시킬 것인가에 관한 문제에 이성적 행동이론을 어떻게 적용시켜야 하는가?

첫 번째 단계로, 연구자는 구단주가 이 목표를 달성하기 위해 할 수 있는 모든 이성적인 행위들을(예: 유능한 신인선수의 스카우트, 감독에게 우승압력, 선수들에게 우승 보너스를 지급하는 것 등) 분류해야 할 것이다. 이러한 과정은 매우 지루할 뿐만 아니라 상당히 어려운 것이기도 하다. 왜냐하면 사람들은 같은 목표를 추구하는 데 있어서도 종종 다른 방식들을 가지고 있기 때문이다.

그 다음 단계로, 연구자는 각 행동들을 수행하는 구단주의 의도를 결정해야만 한다. 그리고 나서 전체적 목표달성을 예측하기 위해서는 각 행동들의 다양한 효과들을 고려하여 다양한 행동의도들을 어떤 의미 있는 방식으로 통합해야 한다. 따라서 목표를 종속변수로 연구하기 위해서는 이성적 행동이론은 수정되어야 한다. 이 점을 살펴보도록 한다.

\section{2. 시도이론}

이성적 행동이론이 행동목표나 결과목표를 연구하기 위해서 사용되어진다면 연구결과는 
대체적으로 빈약하기 그지없다(Sheppard et. al, 1988). 그 원인은 이성적 행동에서 목표로 변경함에 따라 발생하는 종속변수의 질적 차이에서 기인한다.

Fi shbei n과 Aj zen(1975) 은 이성적 행동이 행동시점에서 개인의 의도에 의해 결정된다고 주장한다. 그러나 목표의 경우에 있어서는 의도와 행동간에 추가적인 요인들이 개입될 수가 있다(Bagozzi 1992). 이 요인들은 개인이 상황을 의식적으로 통제하는 정도와(Aj zen 1985), 개인이 목표를 성취하려고 시도하는 정도를 포함한다. 노력 혹은 시도는 개인 의도의 행위적 표현이며, 통제는 시도가 성공 흑은 실패로 이르는 가를 결정하는 것이다(Bagozzi et. al, 1990).

시도하려는 의도는 목표상황에 있어서의 시도를 결정한다. 이는 이성적 행동이론에 있어 의도가 이성적 행동을 결정한다는 것과 같은 맥락이다. 시도와 목표성취간의 관계는 부분적으로 개인의 통제를 넘어서는 요인들에 의존하고 있다. Sheppard(1988) 의 분석은 이 논거를 뒷받침해준다. 이에 따르면 의도와 목표간의 상관관계는 의도와 행동간의 상관관계보다 휠씬 더 약한 것으로 발견되었다. 마찬가지로 Bagozzi, Yi, Baungartner (1989)는 의도가 실제 목표 달성보다는 목표를 달성하려는 시도와 더욱 강하게 관련되어있다는 것을 발견했다.

목표를 포괄할 수 있도록 이성적 행동이론을 수정하는 첫 단계는 종속변수로서 행동을 시도로 대체하는 것이다. 시도는 이성적 행동의 경우에 있어 행동에 상당하는 개념이기 때문에 이렇게 바꾸더라도 일반성을 상실하지 않는다.

모든 변수들이 시간, 행동, 표적, 상황들에 있어서 동일하게 규정되어져야 한다는 일치기준(correspondence criteria) 에 의해서, 우리는 이성적 행동이론에 있어서 행동의 결정변수들을 시도에 적합하도록 재구성해야한다. Fi shbei n과 Aj zen(1975)에 의하면 행동은 행동하려는 의도에 의해 결정되고, 의도는 행동에 대한 태도와 사회적 규범에 의해 결정된다고 하였다. 그러므로 목표지향적 행동에 이를 똑같이 적용하면 다음과 같다. 목표를 성취하려는 시도는 시도하려는 의도에 의해 결정되고, 이 시도 의도는 시도에 대한 태도와 사회적 규범에 의해 결정된다.

이성적 행동이론과 시도이론간의 이러한 미묘한 차이는 사람들이 어떻게 태도와 주관적 규범, 의도를 형성하고 이러한 변수들이 어떻게 행동을 낳는가에 대해 깊은 의미를 함축하고 있다.

이성적 행동이론을 수정하는 두 번째 단계는 목표지향적 행동을 설명할 수 있도록 태도를 재정의하는 것이다. 이를 위해 우리는 태도를 3가지로 구성된 것으로 본다.

(1) 목표 달성이나 행동 수행의 성공에 대한 태도

(2) 목표 달성이나 행동 수행의 실패에 대한 태도

(3) 성공이나 실패로 이르기까지의 활동이나 과정에 대한 태도

다음으로, 성공에 대한 태도나 실패에 대한 태도가 그 자체로서는 목표를 추구하느냐, 
마느냐를 결정하는 데 영향을 미치지 않는다는 사실을 인식하는 것이 중요하다. 성공에 대한 태도 $\left(A_{s}\right)$ 와 실패에 대한 태도 $\left(A_{f}\right)$ 는 목표가 달성될 것이라는 기대 또는 그렇지 않을 것이라는 기대와 각각 상호작용한다고 가정된다. 즉 $\mathrm{A}_{\mathrm{s}}$ 와 $\mathrm{A}_{\mathrm{f}}$ 가 성공과 실패에 대한 기대 $\mathrm{E}_{\mathrm{s}}$, $\mathrm{E}_{\mathrm{f}}$ 와 각각 상호작용한다고 본다. 목표달성의 기대는 Bandura가 제시한 결과기대(outcone expectancy)와 의미가 흡사하다. 그러나 이는 자신이 행동을 충분히 수행할 수 있다는 자신감에 해당하는 자기효능(self-effi cacy)과는 구별되는 개념이다.

곱셈항들을 태도의 요소로 $\mathrm{A}_{s} \mathrm{E}_{s}$ 와 $\mathrm{A}_{\mathrm{f}} \mathrm{E}_{\mathrm{f}}$ 를 개념화하는 것은 Lewi $\mathrm{n}$ 의 생각과 (Lewi $\mathrm{n}$, Denbo, Festinger, and Sears 1944) 다소 흡사하다. 그는 목표의 극성(val ence) 은 성공의 극성과 성공 가능성의 곱에서 실패의 극성과 실패가능성의 곱을 뺀 것과 같다고 주장하였다. 그러나 이처럼 차감에 의해서 여러 곱셈항들을 단일항으로 통합하는 대신에 우리는 곱셈항들 - $\mathrm{A}_{\mathrm{s}} \mathrm{E}_{\mathrm{s}}$ 와 $\mathrm{A}_{\mathrm{f}} \mathrm{E}_{\mathrm{f}}$ 가 각기 개별적인 결정변수라고 제안한다. 요컨대, 성공하려는 욕망이 있다는 것이나 실패에 대한 두려움이 없다는 것 그 자체는 의사결정의 예측지표로서 충분하지 않다. 이런 태도들이 예측된 결과를 산출할 수 있기 위해서는 성공이 가능하다는 기대와 실패가 없으리라는 기대를 각각 수반해야 한다.

이러한 사실들을 기반으로, 태도가 미치는 영향을 보여주는 4 개의 함수식을 가정한다. 이 식들은 3 개의 태도요소들이 가산적이거나, 상호작용적인 결과를 갖거나, 직접적인 결정변수로 작용하거나, 또는 시도에 대한 고차원적인 태도 $\left(A_{t}\right)$ 로 변형될 때 나타나게 된다. 4 개의 식은 다음과 같이 나타낼 수 있다. (해석의 편의를 위해서 회귀방정식으로 나타냄)

식 $1:$ 가산적으로 분해된 태도

$$
I=a+b_{1} A_{s} E_{s}+b_{2} A_{f} E_{f}+b_{3} A_{p}+e
$$

식 2 : 곱셈적으로 분해된 태도

$$
I=a+b_{1} A_{s} E_{s} A_{f} E_{f} A_{p}+e
$$

식 $3:$ 가산적 고차원 태도

$$
\begin{aligned}
& A_{t}=a+b_{1} A_{s} E_{s}+b_{2} A_{f} E_{f}+b_{3} A_{p}+e \\
& I=a+b A_{t}+e
\end{aligned}
$$

식 4 : 곱셈적 고차원 태도

$$
\begin{aligned}
& \text { At }=b_{1} A_{s} E_{s} A_{f} E_{f} A_{p}+e \\
& I=a+b A_{t}+e
\end{aligned}
$$

여기서 $a$ 와 $b_{i}$ 는 추정된 계수, $\mathrm{e}$ 는 오차항목, $\mathrm{I}$ 는 의도이다. 나머지 기호들은 이제까지 정의된 바와 같다.

식 1과 3은 성공, 실패, 과정에 대한 고려가 독립적이고 보완적인 결과를 낳을 때 적용된다. 예를 들어 이 식들은 태도요소 중의 하나만이라도 높을 때 호의적 의사결정이 내려지는 경우에 적절하다. 대조적으로 식 2 와 4 는 결정이 태도요소간의 상호작용에 의해 
영향을 받는 경우에 적절하다. 예를 들어, 호의적인 의사결정을 위해서는 $\mathrm{A}_{\mathrm{s}} \mathrm{E}_{\mathrm{s}}, \mathrm{A}_{\mathrm{f}} \mathrm{E}_{\mathrm{f}}, \mathrm{A}_{\mathrm{p}}$ 모두 높은 점수가 필요한 것이다.

$\mathrm{A}_{\mathrm{t}}$ 에 대한 필요성은 여러 분리된 태도들이 하나로 통합될 때 나타난다. 이것은 의사결정자의 마음속에서 자극물이 단순화될 때, 태도가 계층적인 표현으로서 기억 속에 저장될 때, 혹은 인지적 일관성 같은 심리적 메커니즘에 의해 정신적인 표현이 수렴할 때 발생한다.

그림1은 시도이론과 우리가 이제껏 제시한 변수들을 나타내고 있다. 그림1의 다른 변수들을 논의하기 전에 우리는 시도이론과 유사한 2 개의 최근이론에 대해 언급하고자 한다.

<그림 1> 시도이론

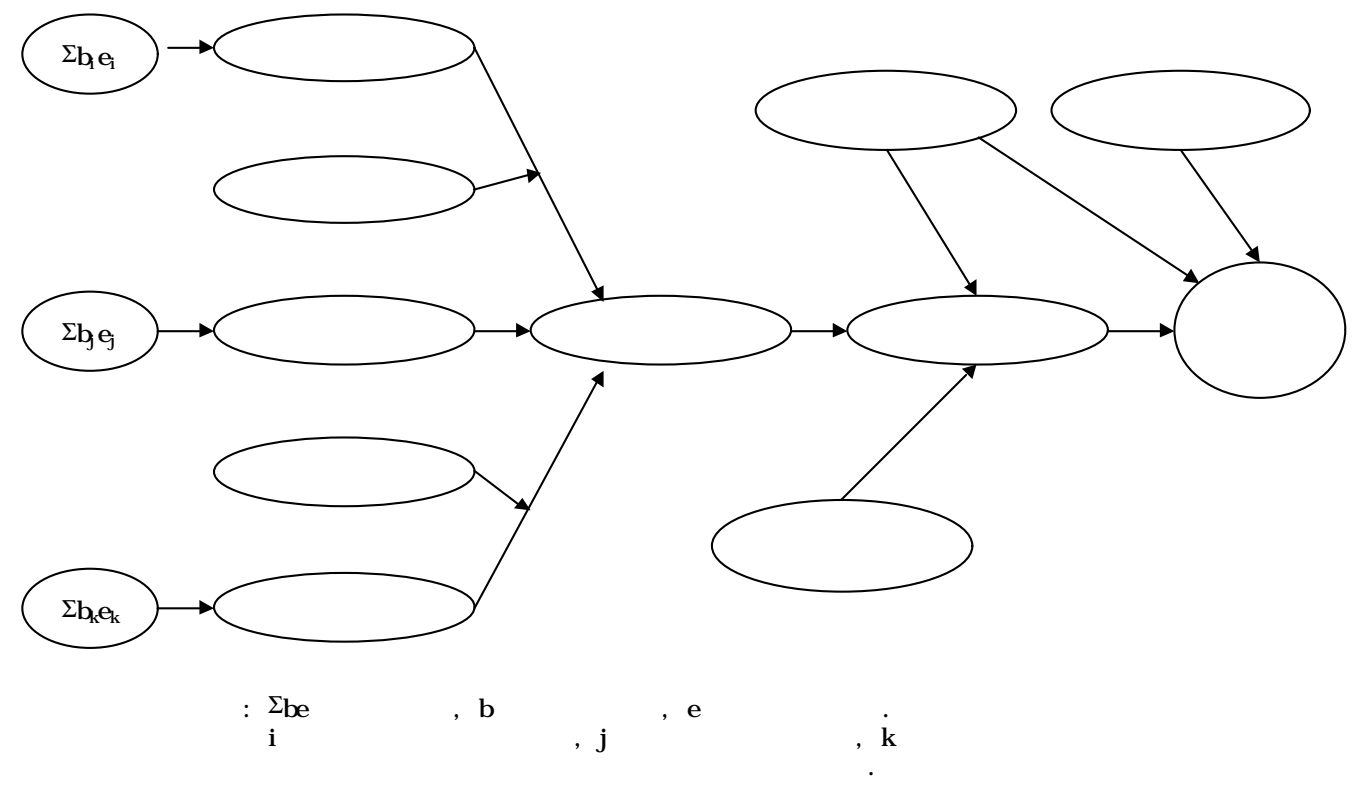

첫 번째 이론은 Aj zen(1985)이 제시한 계획된 행동이론(Theory of Pl anned Behavi or)이다. 이 이론은 시도이론과 유사하지만 목표추구과정에서 대한 태도 $\left(A_{p}\right)$, 과거시도의 빈도, 과거시도의 최근성이 포함되어 있지 않다. 그리고 그는 주관적 규범의 정의에 있어서 우리가 제시하듯이 시도에 초점을 맞추지 않고, 이성적 행동이론에 사용되었던 방법을 사용하였다.

Aj zen은 과정과 관련된 고려가 성공적/실패적 행위시도에 대한 태도에 반영되었기 때문에 그의 이론에 $\mathrm{A}_{p}$ 를 포함시키지 않았다. 물론 이 것은 개념타당성(construct val idity) 의 이슈이며 실증적으로 다루어야 할 것이다. 그가 의도와 시도의 결정변수로서 과거시도를 고려하지 않은 이유는 불확실하다. 아마도 이러한 변수들이 태도와 주관적 
규범에 영향을 미쳐서 시도와 의도에도 간접적으로 영향을 미친다고 생각했거나, 그렇지 않으면 이 변수들이 의도에 대한 태도와 주관적 규범의 효과를 조정한다고 생각했기 때문에 과거시도를 고려하지 않았을 것이다(Fi shbei n and Aj zen 1975 p. 303). 또한 그가 주관적 규범을 시도에 영향을 주는 변수로서 정의하지 않은 이유도 불확실하다. 그러나 그는 이것을 간과했던 것 같다. 사실상 $\mathrm{Aj}$ zen(1985) 은 그의 계획적 행동이론(theory of planned behavi or)에서 태도와 의도의 대상을 행동에서 시도로 바꿀 필요성을 충분히 설명하지 않았다.

시도이론과 유사한 또 하나의 이론은 Warshaw, Sheppard, Hartwick이 제시한 목표추구이론(Theory of goal pursuit)이다. 실제로 그들의 이론은 1980년대 초기 이후로 연구논문 형태로 존재해 있었는데, Aj zen(1985)에 의하여 발견되었다. 목표추구이론은 2가지 근본적인 면에 있어 시도이론과 차이가 있다. 첫째, 계획된 행동이론과 마찬가지로 이 이론은 과거시도를 고려하지 않는다. 둘째, $A_{s} E_{s}, A_{f} E_{f}, A_{p}$ 가 $A_{t}$ 와 I의 세 가지 개별적 결정변수로 작용한다고 본 시도이론과는 달리, 이 이론은 다소 모호하게 이 변수들을 별 차이 없는 하나의 변수로 합쳐 버린다(War shaw and Davis 1985, p. 224). 이 차이점들은 또한 개념타당성(construct validity)과 관련된 것으로 실증적으로 검사되어야 할 것이다.

그림 1 에 있어 또 한가지 주목할 점은 각각의 태도요소인 $A_{s}, A_{f}, A_{p}$ 가 자기들만의 고유한 결정변수 집합을 가지고 있다는 것이다. 즉 각 태도는 신념(b) 과 평가(e) 의 곱의 총합에 의해 영향을 받고, 여기서 각 태도요소마다 개별적으로 $\mathrm{b}$, e가 존재하고 있다.

\section{3. 시도이론에 있어 과거시도의 역할}

최근의 연구에 의하면 과거의 행동은 행동의도결정에 있어 태도와 사회적 규범 이외의 독립적인 영향력을 미친다는 사실이 밝혀졌다 (Bagozzi 1981; Bent1er and Speckart 1979; Nanst ead, Proffit, and Smart 1983; Schl egel, Crawford, and Sanborn 1977). 게다가 과거행동은 미래행동에 대해서 단순히 의도를 통한 간접적 영향이외에도 직접적인 영향을 미친다는 사실이 밝혀졌다 Bagozzi 1981, Bentler and Speckart 1979, Wttenbraker, G bbs, \& Kahl er 1983, Landi s, Tri andi s, \& Adanmpdul ous, 1978).

그러나 과거행동에 대한 기존 연구는 과거시도는 다루지 않았으며 우리가 중요하다고 제시하는 과거빈도(frequency) 와 최근성(recency)의 차이마저 무시해왔다. 이 논문에서는 이러한 이슈들을 고려함으로써 우리는 과거행동들의 영향에 대한 이론적 근거를 마련코자 한다. 비록 이전의 연구가 과거행동의 빈도가 미치는 영향을 실증적으로 보이긴 했지만, 
이러한 결과들이 어떻게 발생하는가에 대해서는 설명이 취약했었다.

\section{1. 과거시도의 빈도}

우리는 과거시도의 빈도(frequency of past trying) 가 시도의도와 시도의 결정변수로써 독립적인 예측력을 더해준다고 제안하고자 한다(그림 1 참조). 이제 이러한 제안의 근거를 살펴보도록 하자.

개인이 시도에 대해 명확한 태도를 가지고 있을 때일지라도, 만약 태도가 과거시도의 완벽한 반영이라기보다는 단지 부분적으로 생성된 추론이라면 과거빈도는 시도의도에 독립적인 영향력을 미칠 수 있다. 시도에 대한 태도가 과거시도의 빈도를 반영할 때는 태도와 과거시도 변수가 상호 관련되어 있을 것이다. 아마도 이는 빈도가 시도에 대한 태도 속에 내재되어 있는 기대치에 영향을 미친다는 사실에서 기인하는 듯하다. 이러한 빈도는 표적행동에 대한 개인의 경험을 반영하고 있으며 이는 한 개인이 성공에 대한 기대, 실패에 대한 기대, 성공 혹은 실패가 특정결과를 낳을 수 있는 가능성 등을 평가하는 데 영향을 미칠 것이다. 과거빈도가 $\mathrm{A}_{t}$ 에 반영되지 않는 범위에서는, $\mathrm{A}_{t}$ 는 개인이 시도에 대해 가지고 있는 모든 스크립트를 반영하게 된다. 이와 관련해 일부학자들은 일상적 행동들은 종종 무심하게 일어나며 이런 행동수행은 스크립트에 의해 결정된다고 주장하기도 하였다 (Abel son 1976, Langer 1976). 우리는 행동을 무심함( mindl ess) 과 세심함( mindf ul) 이라는 양 극단의 연속선상에 있다고 보는 것이 유용하다고 생각한다. 모든 행동들은 정도의 차이는 있지만 양 측면에 의해 결정된다고 볼 수 있는데, 이 정도는 과거빈도가 시도의도에 대해 태도나 사회적 규범이외의 영향을 미치는 정도로 나타난다.

한 개인이 어떤 행동에 대해 지닌 태도와 의도가 불확실하다면 시도의도에 대한 과거빈도의 독립적인 영향력은 횔씬 강력할 것이다 (Bagozzi and Yi 1989). 이러한 경우는 예를 들어 몇 년 후에 차를 구입한다는 것처럼 개인이 구체적인 행동계획을 세우기에는 시점이 나무 멀 때 발생할 것이다. 이런 경우 만일 개인이 의도에 대해 질문을 받는다면 의도라기보다는 자신의 행동에 대한 기대를 답할 것이며 과거빈도의 영향력이 높아지게 된다. 다음의 예를 살펴보자. 누군가가 지난 달에 일주일에 한 두 번 정도 애인과 데이트를 즐겼다고 한다면 질문 받을 당시 미래에 대한 별 계획이 없다면 다음 달에도 그렇게 할 것이라고 대답할 것이다. 만일 이 답변한 의도가 기대를 뜻하는 것이라면, 과거빈도는 대답한 시도의도의 가장 좋은 예측치가 될 것이다.

좀 더 일반적으로 말한다면, 인식된 행동가능성이 태도나 사회규범의 예측치보다 더 크거나, 더 적을 때 과거빈도는 답변한 시도의도를 예측하는 데 도움을 줄 것이라고 기대할 수 있다. 왜냐하면 인지와 평가는 부단히 변화하고, 혹은 성공과 실제기대치에 반영된 
지각된 통제가 자기인식이나 이해의 부족 때문에 실제적 통제와는 틀리기 때문이다.

과거시도는 또한 미래시도에 독립적인 예측력을 더해준다.

첫째, 과거시도는 시도가 단지 시도의도에 의해서만 결정되지 않을 때 작용할 수 있다. 즉 기회부족이나 내적 장애요인 때문에 의식적 의도가 실제적 시도로 전환되지 않을 때 발생할 수가 있는 것이다,

둘째, 한 개인이 자신의 의도가 확실치 않다고 여길 때 과거빈도는 이후의 시도에 대해 직접적으로 영향을 미치거나 태도를 통해 간접적으로 영향을 미칠 것이다(Bagozzi and Yi 1989) .

\section{2. 과거시도의 최근성}

사람들은 최근에는 시도하지 않았으나 오랫동안 시도했던 경험을 가지고 있을 수 있다(예: 정기적으로 주택복권의 당첨을 시도). 또한 그 반대의 경우도 있을 수 있다(예: 복잡한 도심을 주행하려는 초보운전자). 비록 과거시도의 빈도와 최근성이 다른 개념이라 할지라도 그들은 상호 연관되어 있다. 누군가가 최근에 어떤 행동을 했다는 것은, 적어도 부분적으로는, 그 행동이 수행되어진 빈도를 반영할 수밖에 없다.

실제로 과거의 연구에 의하면(Bird and Ehrenberg 1966) 과거시도의 빈도와 최근성이 상호 관련되어 있다는 것을 밝히고 있다. 그럼에도 불구하고, 의도와 빈도의 영향을 통제한 뒤에도 최근성이 시도에 대해 독자적인 영향을 미친다고 본다.

시도모형에 있어 여러 변수들에 대한 최근성의 영향은 두 가지 방식으로 발생할 수 있다.

첫째, 최근성은 표적행동에 대한 전반적인 경험의 일부이므로, 빈도를 통해 작용할 것이다. 그리고 시도의도에 내재되어있는 여러 변수들에 영향을 미칠 것이다.

둘째, 최근성은 모든 기대의 측정치에 어떤 편향(bi as)을 야기한다. Tversky와 Kahneman(1974)이 밝힌 것처럼, 내재적인 편향은 불확실한 내. 외적 상태에 대한 주관적 확률 추정치의 정확성을 제한한다. 따라서 성공의 기대측정치는 임의오차뿐만 아니라 체계적인 편향때문에 성공의 기대 실제값과는 차이가 있을 수 있다(Kal wani and Silk 1982; Sl ovi c, Fi schhoff, and Lichtenstein 1977). 이런 결과는 시도의도에도 발생한다. 왜냐하면 시도의도가 주관적 확률로 측정하는데 사람들은 행위의 수행이나 결과의 성취를 시도해 보게 될 가능성을 추정한다(Ajzen and Fi shbein 1980, 부록 1). 과거시도에 의해 생기는 특수 편향들은 이용가능성( avai I abi l i ty). 닺내림(Anchor i ng)/적응( Adj ust ment) 효과들이다. 이용가능성 휴리스틱이라는 것은 과거경험이나 관련된 연상이 마음 속에서 떠오르기 쉬운 정도가 주관적인 확률추정에 많은 영향을 미친다. 나아가 "최근의 발생사건들은 이전의 사건들보다 상대적으로 이용가능하다"(Tversky, Kahneman 1974, 
pp. 1127). 이것이 의미하는 바는 좀더 이용가능한 최근의 사건들이 시도의도의 형성과 여타 기대판단에 있어 보다 중요할 것이라는 것이다.

이용가능성편향이 의도치에 영향을 미친다는 몇몇 증거가 Ander son(1983)에 의해 제시되었다. 최근성은 아마도 자기효능인식에 영향을 미침으로써 그 효과를 발휘한다. 이 과정에서 최근사건에 대한 기억의 이용가능성 때문에 성공 또는 실패가 강조되는 정도에 따라 성공이나 실패기대치가 높게, 혹은 낮게 편향된다. 예를 들어 막 첫 번째 판매를 한 신참사원은 이후 판매에 대한 그의 능력에 대해 지나치게 높은 기대를 할 수가 있다. Cervone과 Peake( 1986) 도 이와 같은 점을 지적한 바 있다.

닻내림과 적응휴리스틱도 같은 효과를 가질 것이다. 사람들은 종종 최초의 값을 고려하고 난 다음, 그것으로 여러모로 변화시키며 최종적인 주관적 확률의 예측치에 도달하는 데 이는 최초기준에 의해 편향되곤 한다. 최근의 사건들이 기억 속에서 좀더 이용가능하기 때문에, 과거시도의 최근성도 역시 장기적인 시도빈도보다 기대형성의 기준점이 될 가능성이 훨씬 더 높다.

최근성에 의해 발생한 편향들이 모든 기대측정에 영향을 미치기 때문이 그 효과들은 시도의도와 시도의도의 여러 결정변수들(성공기대, 실패기대, 행동결과 가능성) 에게 나타날 것이다. 이 편향들은 등식 양쪽에서 발생하기 때문에 최근성은 독립적으로 시도의도를 예측할 수는 없지만 시도예측에는 기여할 수가 있다. 왜냐하면 시도라는 것은 기대가 아니어서 의도에 나타나는 편향들을 반영하지 않기 때문이다.

최근성의 독립적인 예측력은 시도자체가 시도의도에 발생하는 펀향들에 의해 어떻게 영향을 받느냐에 달려있다. 만일 실제시도가 영향을 받지 않는다면, 최근성은 오직 시도예측방정식에 있어 억제변수(suppressor vari able) 로만 작용할 것이다. 즉, 시도의도에 있어 너무 큰 역할을 수정하기 위해서 부정적인 가중치를 갖게 될 것이다. 이 가중치는 최근성이 개인의 장기적 시도빈도를 대표하지 못할수록 더 커질 것이다.

하지만 실제 시도가 시도의도의 최근성편향에 의해 영향을 받을 가능성은 더 높다. Campbel I 과 Fai rey(1985), Sheman( 1981)은 이용가능성편향이 자기실현적 예언상태를 띄는 기대를 낳을 수 있다는 것을 보여주었다. 만일 그렇다면, 시도는 최근성의 방향으로 영향을 받을 것이다. 그리고 그 효과는 과거시도에 대해 최근성의 대표성이 줄어들수록 더 커질 것이다.

그림 1은 앞에서 제시된 모든 변수뿐만 아니라 최근성과 빈도의 가정된 효과들을 보여준다. 시도이론은 이성적 행동이론을 시도와 목표지향적 행동의 연구로 확장시킨 모든 연구들을 포괄하는 광범위한 체계를 보여준다. 


\section{4. 시도이론의 검증}

체중을 줄이려는 사람들을 대상으로 해 시도이론을 검증했다. 240 명의 미국 미시간 대학교의 대학생들 240 명이 본 조사에 참여하여 3 주 동안 매주 한번씩 질문서를 작성하였다. 그림 1 에 있는 각 변수들은 다음과 같은 항목들에 의해 측정되었다.

시도의도나 다른 변수들이 다음 주에 시도할 것에 대해 측정했기 때문에 한 주일이 끝날 때마다 시도( T, trying) 를 측정하였다. 구체적으로는 응답자들이 해당 주에 체중을 줄이고자 시도하였는가를 예/아니오 척도에 표시하도록 하였다. 과거시도의 빈도(Tyr)는 일 년기간에 대해 측정했는데 ' 지난 1년간 나는 체중을 줄이기 위한 시도를 했다' 라는 질문에 대해 6 점 척도에 응답했다: $1=$ 아주 여러 번, $2=$ 여러 번, $3=$ 서너번, $4=$ 두세 번, $5=$ 한번, $6=$ 한번도 없음. 태도, 신념, 평가, 기대, 사회적 규범, 의도를 측정할 때마다 이는 측정했다. 과거시도의 최근성을 측정하기 위해서는 지난 주 동안의 시도(Twk)를 사용했다. 최근 과거가 어느 정도이냐는 사실 주관적인 사항이지만 체중감소시도는 자주 있는 것이고 다른 연구에서 일 주 단위가 효과적으로 사용되었기 때문에 본 연구에서도 일주일을 최근성의 기간으로 사용했다. 응답자들은 지난 일 주일 동안에 체중 감소시도를 했는가를 표시하도록 했다.

결과의 가능성에 대한 신념(bel i efs, b) 은 각 결과가 발생할 가능성에 대해 7점 척도로 응답했다: 전혀 없다, 없다, 약간 없다, 중간이다, 약간 있다, 있다, 매우 있다. 결과의 평가(eval uation, e) 는 각 결과에 대해 ' 즐거운/불쾌한' 척도를 사용해 측정했다. 이 척도는 ' 좋은/나쁜' 척도에 비해 감정을 측정하는데 효과적이라고 밝혀진 바 있다(Aj zen and Fi shbei n 1980, p. 91).

시도의도(Intention to Try, It)는 "나는 다음주동안에 체중을 줄일 시도를 할 것이다" 라는 항목으로 측정했다. 시도에 대한 태도(Attitude toward Trying, At)는 " 다음주에 체중을 줄이기 위한 시도를 한다는 것은 나를 -..-하게 만든다" 라는 질문에 대해 4개의 항목으로 측정했다: 즐거운/불쾌한, 좋은/나쁜, 신나는/역겨운, 만족스런/불만스런. 시도성공에 대한 태도(As)는 "다음주에 체중감소를 시도해 성공한다면 나는 -.-할 것이다” 라는 질문에 대해 시도에 대한 태도에 사용된 항목으로 측정했다. 이와 마찬가지로 시도실패에 대한 태도(Af)는 “다음주에 체중감소를 시도해 실패한다면 나는 -.-- 할 것이다" 라는 질문으로, 시도과정에 대한 태도(Ap)는 "다음주에 체중감소를 시도한다면 성공/실패에 관계없이 나는 --- 할 것이다" 라는 질문으로 측정했다.

성공이나 실패에 대한 기대는 7점 척도로 측정했다. 성공 기대(Es)는 "내가 다음주에 체중감소를 시도한다고 가정할 때 실제로 체중을 감소할 가능성이 -..-하다" 라는 
질문으로 측정했다. 실패기대(Ef)도 "내가 다음주에 체중감소를 시도한다고 가정할 때 실제로 체중을 감소하는 데 실패할 가능성이 --.하다." 라는 질문으로 측정했다. 마지막으로 시도에 대한 주관적 규범(SN) 은 “ 내게 중요한 사람들 대부분이 내가 다음주에 체중을 줄이기 위한 시도를 해야한다하고 생각한다" 라는 질문에 대해 7점 척도로 측정했다.

자료를 분석하기 위해서는 세 가지 방법들이 사용되었다. 첫째, 개념타당성은 구조등식모형(Bagozzi, Yi 1990, Jor eskog, Sorborn 1988) 을 이용하여 검사하였다. 다음으로 그림1의 종속변수가 구간척도로 측정된 경우, 다중회귀분석이 가설검증을 위해 사용되었다. 마지막으로 종속변수가 이원지표(예/아니오)로 측정될 경우 로짓분석( Maddal a, 1983)이 이용되었다.

\section{1. 개념타당성}

다양한 태도의 제시가 시도이론의 중심특징이기 때문에 태도측정치들이 개념타당성을 획득할 수 있느냐는 중요한 문제이다. 수렴타당성과 판별타당성은 다속성 다측정방법행렬(MMM multitrait, multimethod matrix)의 검사를 통해 확인될 수 있다. 이는 8개의 태도측정치 $\left(\mathrm{A}_{\mathrm{s} 1}, \mathrm{~A}_{\mathrm{s} 2}, \mathrm{~A}_{\mathrm{f} 1}, \mathrm{~A}_{\mathrm{t} 2}, \mathrm{~A}_{\mathrm{p} 1}, \mathrm{~A}_{\mathrm{p} 2}, \mathrm{~A}_{\mathrm{t} 1}, \mathrm{~A}_{\mathrm{t} 2}\right)$ 의 상관관계로 형성되어 있으며, 두 시점에서 측정했으므로 2 개의 $8 \times 8$ 행렬으로 나타난다. MM늘 분석하는 가장 엄격한 방법은 구조등식모형의 이용이다.

$\chi^{2}$ - 적합도의 검증( $\left.\chi^{2}, \mathrm{df}\right)$, 적합도 검정지수(goodness- of-fit undex), $\mathrm{RMR}$ ( root mean square resi dual) 측정치는 개념타당성정도의 지표를 제공한다(Jor eskog and Sorborm 1988). 어떤 의미에서는, 이것이 가장 유사한 방법들이 이용되었기 때문에 약한 검사 방법일수도 있다. 하지만 구조등식 방법은 측정오차를 고려하기 때문에, 상관계수에 기초한 수렴타당성 (convergent val idity) 의 전통적인 분석방법보다 훨씬 뛰어나다.

개념타당성에 있어 비록 $\chi^{2}$ 검증이 첫 번째, 두 번째 검사 모두 유의했지만 $\chi^{2}(14)=$ $67.5, \mathrm{p}<.01, \chi^{2}(14)=53.6 \mathrm{p}<.01$ ), GFI 측정치 (첫번째 . 93, 두번째. 95)는 이 모형이 실제적으로 매우 높은 분산량을 설명하고 있다는 것을 보여준다. RMR측정치(첫번째 . 04, 두번째 .03)는 평균적으로 잔차분산과 공분산이 소량으로 존재한다는 것을 보여준다. 그러므로 결국 태도 측정치는 개념타당성을 나타낸다.

판별타당성 (di scri minant val i di ty) 은 특성들 사이의 상관관계 분석을 통해 검사될 수 있다. 판별력은 각 상관관계가 각 표준오차를 2 배한 것보다 더 큰 양으로써 1 보다 작을 때 달성된다. 유사한 방법들이 사용되었기 때문에 이 검사법은 가장 상이한 방법들이 사용된 것보다 훨씬 더 엄격한 판별타당성 검증이라 할 수 있다. 다시 말해서, 유사한 방법들이 사용되면 훨씬 더 큰 공분산이 예상될 수 있다. 이는 측정치간의 상관관계를 팽창시키고 
판별타당성을 입증하는 것을 더욱 어렵게 만들 수가 있다.

판별타당성의 결과는 표 1 에 나타나 있다. 태도개념들 사이의 모든 조합에 있어 상관관계가 각각의 표준오차의 2 배 이상으로 1 보다 적다. 이 중에서 제일 낮은 판별타당성은 $A_{t}$ 와 $A_{p}$ 사이의 경우이다. 여기서 상관관계는 1보다 0.33이 적다.(1.00 0.67=0.33) 그리고 상응하는 표준오차의 2 배보다 $(2 \times .04=08)$ 훨씬 크다. 이 표는 중심적인 상관관계들이 측정상의 신뢰성 문제를 수정하였고, 그들이 방법상의 분산을 잠재적으로 공유하고 있으므로 또 이 검증법이 보수적이라는 사실을 고려할 때, 태도측정치간에 명백한 판별타당성이 존재한다고 볼 수 있다.

<표 1> 태도들간의 상관관계

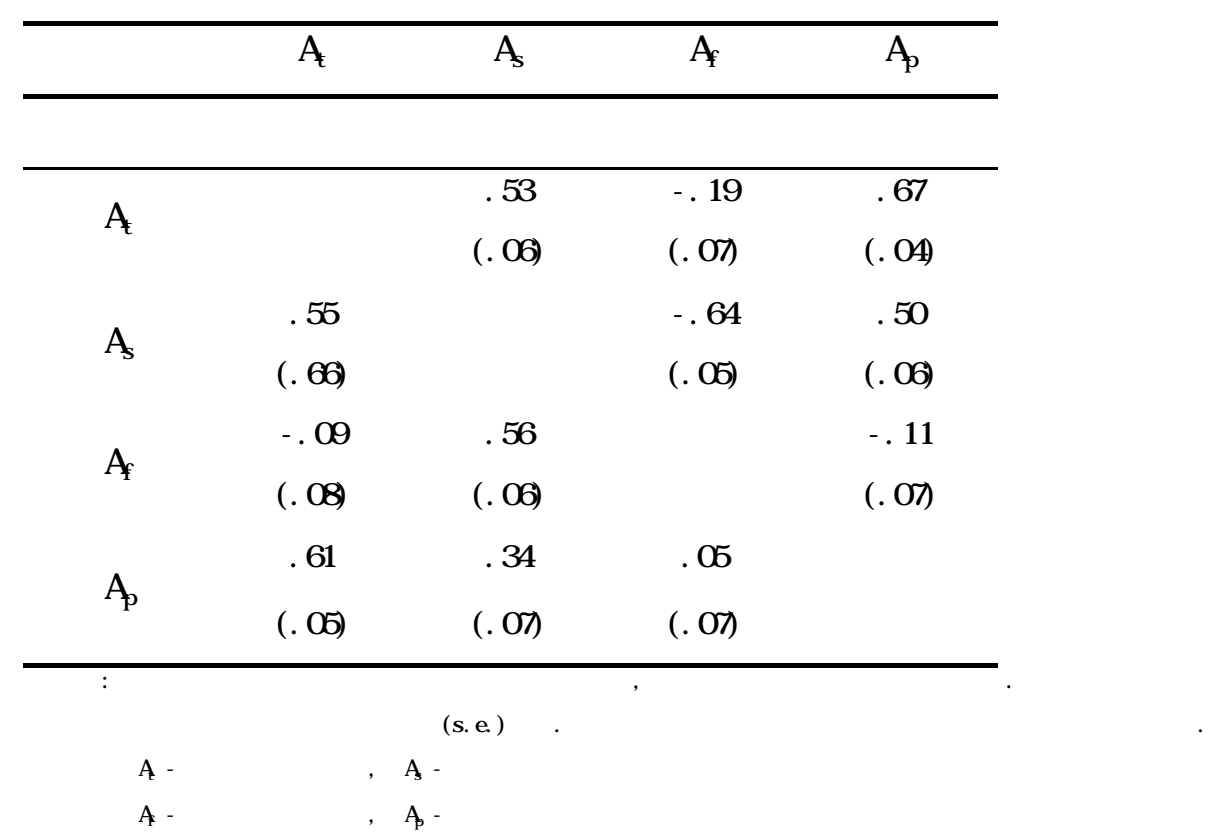

\section{2. 시도( $T)$ 의 설명}

표 2는 계수추정치와 체중을 줄이려는 시도 $(T)$ 의 분산중 모형이 설명하는 분산을 요약한 것이다. 계획된 행동이론(TPB)에 의해 예측된 바로는, $\mathrm{I}_{\mathrm{t}}$ 는 2 번 모두 T에 유의적인 분산을 설명해준다. ( 첫번째 $\mathrm{R}^{2}=.29$, 두번째 $\mathrm{R}^{2}=.41$ ).

시도이론(TT) 에 의해 설명되어지는 체중감량시도의 분산은 TPB의 수치보다 높다(첫번째 $R^{2}=.45$, 두번째 $\left.R^{2}=.61\right)$. 즉 우리의 가설을 확인할 수 있다.

또한 가정된 대로 $\mathrm{I}_{\mathrm{t}}$ 와 $\mathrm{R}$ 모두 두 번의 시점에서 유의한 예측변수이다. $\mathrm{R}$ 에 있어서, 전 주에 체중감량을 시도했다고 답한 실험대상자는 첫 번째는 $26 \%$ 이었고 두 번째는 $28 \%$ 이었다. 
기대와는 달리 $F$ 는 유의한 예측변수가 아니었다.

<표 2> 시도를 예측하는 모형의 결과

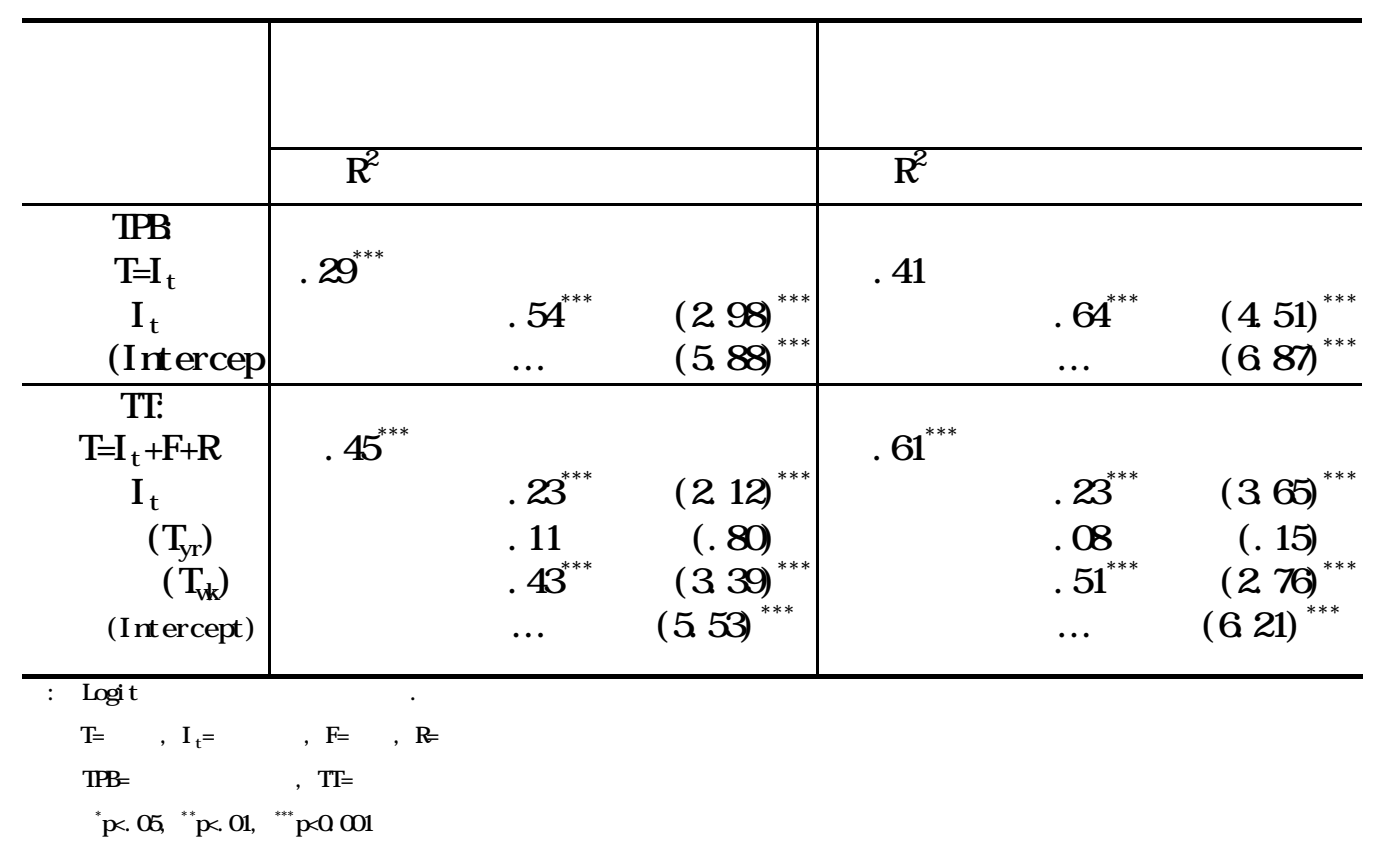

\section{3. 시도의도 $\left(I_{t}\right)$ 의 설명}

표 3은 경쟁모형에 의해 설명되어지는 체중감량 시도의도 $\left(I_{t}\right)$ 의 분산을 요약했다. TPB가 예측했듯이, 2 개의 독립변수 $A_{t}$ 와 SN가 두번 모두 시도의도의 분산들의 상당한 부분을 설명하는 것으로 나타난다 첫번째, 두번째 모두 $\mathrm{R}^{2}=44$ ). 또한 각 종속변수는 각 시점에서 유의한 베타값을 가진다.

$\pi$ 모형은 추가독립변수 F룰 포함하고 있다. 결과는 TT모형이 두 번 모두 TPB모형보다 $\mathrm{R}^{2}$ 이 높다. (각각 $\mathrm{R}^{2}=.59, \mathrm{R}^{2}=61$ ) 위계적 회귀분석을 통한 $\mathrm{F}$ 검증을 하면, 이 증분값은 $a<001$ 일 경우에 유의하다. 가정된 대로 $\mathrm{A}_{\mathrm{t}}, \mathrm{SN}_{\mathrm{t}}, \mathrm{F}$ 는 두 번 모두 $\mathrm{I}_{\mathrm{t}}$ 의 유의한 예측변수가 되었다 
<표 3> 시도의도를 예측하는 모형의 결과

\begin{tabular}{|c|c|c|c|c|}
\hline \multirow{2}{*}{ 모형 } & \multicolumn{2}{|c|}{ 첫번째 } & \multicolumn{2}{|c|}{ 두번째 } \\
\hline & $\mathrm{R}^{2}$ & 베타 & $\mathrm{R}^{2}$ & 베타 \\
\hline \multicolumn{5}{|l|}{ TPB: } \\
\hline $\mathrm{I}_{\mathrm{t}}=\mathrm{A}_{\mathrm{t}}+\mathrm{SN}$ & 44 & & .44 & \\
\hline$A_{t}$ & & .49 & & .42 \\
\hline SN & & .33 & & .38 \\
\hline \multicolumn{5}{|l|}{ TT: } \\
\hline $\mathrm{I}_{\mathrm{t}}=\mathrm{A}_{\mathrm{t}}+\mathrm{SN}$ & .59 & & .61 & \\
\hline$A_{t}$ & & .33 & & .24 \\
\hline SN & & .20 & & .24 \\
\hline 빈도 $\left(\mathrm{T}_{\mathrm{yr}}\right)$ & & .45 & & .49 \\
\hline \multicolumn{5}{|c|}{ 주: TPB와 TT모형 사이의 $\mathrm{R}^{2}$ 의 차이는 양기간 $\mathrm{p}<.001$ 일 때 유의하다. } \\
\hline
\end{tabular}

4. 4. 시도에 대한 태도 $\left(A_{t}\right)$ 의 설명

표 4는 모형에서 설명되는 시도에 대한 태도 $\left(A_{t}\right)$ 의 분산을 요약하였다. 두 개의 $\mathrm{A}_{\mathrm{t}}$ 등식은 곱셈으로 이루어진 변수들을 포함하고있다. 그러므로 이 변수들에게 유의한 F검증을 할 수 있는 위계적 회귀분석을 이용해 자료를 분석하는 것이 필요하다(Cohen 1978). 그러치 않으면 모든 측정치가 비율척도이어야 하는데 이는 여기의 질문서 자료로서 얻기 힘들다.

표 4의 중앙상단부분은 $\mathrm{A}_{\mathrm{t}}$ 에 대한 TPB 회귀분석결과를 나타내고 있다. 2개의 독립변수 $\left(E_{s} A_{s}\right.$ 와 $\left.E_{f} A_{f}\right)$ 들과 가산적 변수들은 두번 모두 $A_{t}$ 분산의 유의적 부분을 설명한다( 각각 $\mathrm{R}^{2}=.37, \mathrm{R}^{2}=30$ ). 하지만 이 독립변수들은 첫 번 시점에는 베타값이 유의한 반면에 두 번째 시점에는 그렇지 못하다.

표 4의 아랫부분은 TT모형의 사항에 대한 결과치를 보여준다. 가정된 대로 두 번 모두 $\mathrm{R}^{2}$ 가 TTB모형보다 높은 수치를 기록했다 각각 $\left.\mathrm{R}^{2}=.46, \mathrm{R}^{2}=.55\right)$. 각 경우 모두 회귀분석 $\mathrm{F}$ 검증 하에서 $\mathrm{p}<\mathrm{001}$ 일 때 유의하다. 마찬가지로 $\mathrm{E}_{s} \mathrm{~A}_{s}$ 와 $\mathrm{A}_{p}$ 항들도 두 번 모두 $\mathrm{A}_{t}$ 의 유의한 예측치이다. 하지만 $\mathrm{E}_{\mathrm{f}} \mathrm{A}_{\mathrm{f}}$ 는 두 번 모두 유의하지 않다. 
<표 4> 시도에 대한 태도를 예측하는 모형의 결과

\begin{tabular}{|c|c|c|c|c|}
\hline \multirow{2}{*}{ 모형 } & \multicolumn{2}{|c|}{ 첫번째 } & \multicolumn{2}{|c|}{ 두번째 } \\
\hline & $\mathrm{R}^{2}$ & 베타 & $\mathrm{R}^{2}$ & 베타 \\
\hline TPB: & & & & \\
\hline $\mathrm{I}_{\mathrm{t}}=\mathrm{E}_{\mathrm{s}} \mathrm{A}_{\mathrm{s}}+\mathrm{E}_{\mathrm{f}} \mathrm{A}_{\mathrm{f}}$ & $.37^{* * *}$ & & $.30^{* * *}$ & \\
\hline$E_{s} A_{s}$ & & $.29^{* * *}$ & & .08 \\
\hline$E_{f} A_{f}$ & & $.18^{*}$ & & .08 \\
\hline TT: & & & & \\
\hline$A_{t}=E_{s} A_{s}+E_{f} A_{f}+A_{p}$ & $.46^{* * *}$ & & $.55^{* * *}$ & \\
\hline$E_{s} A_{s}$ & & $.22^{* * *}$ & & $.13^{*}$ \\
\hline$E_{f} A_{f}$ & & .11 & & .01 \\
\hline$A_{p}$ & & $.81^{* * *}$ & & $.69^{* * *}$ \\
\hline \multicolumn{5}{|c|}{ 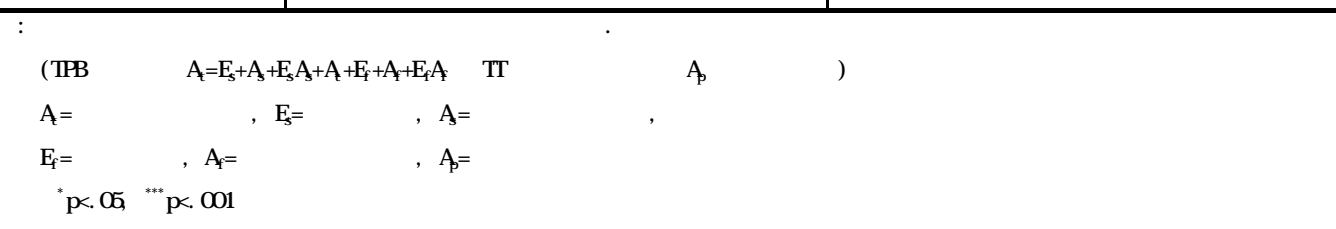 } \\
\hline
\end{tabular}

4.5. 성공, 실패, 과정자체에 대한 태도 $\left(A_{t}, A_{f}, A_{p}\right)$ 에 대한 설명

표 5 에서는 $\mathrm{A}_{\mathrm{s},} \mathrm{A}_{\mathrm{f}}, \mathrm{A}_{\mathrm{p}}$ 가 그들 각자의 곱셈요소들에 의해 얼마나 잘 결정되는가를 검증하고 있다. 여기서도 곱으로 이루어진 독립변수( $\sum$ be항)때문에 위계적 회귀분석을 이용했다.

$\mathrm{A}_{s}$ 와 $\mathrm{A}_{\mathrm{p}}$ 가 두 번 모두 각자의 $\sum$ be 결정변수와 유의하게 연결되어 있는 반면 $\left(\mathrm{A}_{p}\right.$ 의 베타값이 각각.05 $p<0.005, .03 p<001), A$ 는 비록 두 번째 베타값이 유의도( $p<.06)$ 에 가깝지만 유의하지가 않다( 각각 . $00, .05)$. 표 5는 이 결과들을 보여준다.

<표 5> 성공, 실패, 과정에 대한 태도들의 곱셈요소검증

\begin{tabular}{lcl}
\hline 태도개념 & 첫 번째 베타 & 두 번째 베타 \\
\hline$A_{s}=\sum b_{i} e_{i}$ & $0.06^{* *}$ & $0.06^{* *}$ \\
$A_{f}=\sum b_{j} e_{j}$ & 0.00 & 0.05 \\
$A_{p}=\sum b_{k} b_{k}$ & 0.05 & $0.09^{* *}$
\end{tabular}

주: 표의 수치들은 회귀방정식 $\mathrm{A}=\sum \mathrm{b} \sum \mathrm{e}+\sum \mathrm{be}$ 에서 $\sum \mathrm{be}$ 에 대한 표준화되지 않은 베타값이다. ${ }^{*} \mathrm{p}<.005, \quad{ }^{* *} \mathrm{p}<.001$

2000. 03. 


\section{5. 결론}

우리는 우선 $\Pi$ 모형이 특별히 과거시도를 포함하고 있기 때문에 시도와 시도의도를 예측함에 있어 TPB보다 당연히 우월하다는 것을 제시하였다. 이는 두 기간의 결과로 완전히 증명되었다.

첫째, 과거 영향의 포함 유무와 관계없이 시도를 시도에 대한 태도와 사회적 규범과 연결한 완전한 네트워크가 입증되었다.

둘째, TT모형에서 제시된 과거 시도변수들은 상당한 설명력을 더해준다. 또한 빈도와 최근성의 구분이 유용하다는 것도 입증되었다. 그리고 최근의 과거시도가 양기간에 있어 미래시도를 예측하는 데 도움을 준다는 것도 발견되었다. 과거시도의 빈도는 시도를 예측하지는 못했지만 양기간에 있어 시도의도의 유의한 예측치가 되었다. 빈도와 최근성간의 상관관계가 높다고 가정한다면, 빈도가 시도를 예측못하는 이유는 아마도 최근성이 더욱 강력한 예측변수이기 때문이다. 따라서 최근성을 가정했을 때 빈도가 가질 수 있는 어떠한 영향력도 사라질 수가 있다.

그리고 빈도와 최근성의 더 세련된 정의와 측정이 필요한 것이 사실이다. 최근의 과거를 구성하는 것이 행위나 결과의 성질에 따라 상이하기 때문에, TT모형을 여타 목표에 적용시키는 경우 평가하는 체계적인 절차가 개발되어야 한다. 우리의 연구에서는 시도와 최근성 모두가 똑같이 1주일 기간구조를 사용하였기 때문에, 아마도 최근성의 베타값을 높게 편향시켰을 것이다. 두 가지 개념에 다른 기간을 적용하는 것이 더 나을 수도 있다.

시도에 관하여서는 우리연구측정방법이 빈약하다는 것을 인정한다. 이분척도를 사용하는 것보다 연속적인 측정방법을 사용하는 것이 더 나을 수도 있다(하지만 과거시도의 빈도측정은 구간척도를 사용하였다).

최근성과 빈도처럼, 시도와 관련된 2가지 측면이 있다. 어떤 이가 시도를 하느냐, 안하느냐라는 면과, 시도를 한다면 얼마나 일심히 하는지 하는 면이 바로 그것이다(Bagozzi, 1990). 비록 "매우 열심히 시도했다"에서 "전혀 시도하지 않았다"에 이르는 구간척도 측정방법을 사용할 수는 있지만 의도가 형성되고 수행을 하기 전에 발생하는 실제계획, 활동, 경험들의 표현을 개발하는 것이 더 좋을 것이다. (Bagozzi, 1992) 예를 들어, 체중감량을 조사할 때는 하고 있는 활동들의 유형과 수(예: 조깅, 수영, 식이요법, 약 복용, 칼로리 섭취 감소 등), 이러한 중간 활동에 소비되는 정신적, 육체적 노력량, 각 활동을 추구하게 되는 동기부여(체중감량 vs. 사회적인 비감량이유), 성공과 실패의 과거경력, 결과를 경계하고 감시하는 정도 등을 검사하는 것이 수반될 수 있다. 더 나아가서, 비록 
우리가 시도를 내적인 판단으로 취급해왔지만 개인의 자기평가와 좀더 객관적으로 측정하는 것 사이의 관계를 조사하는 것이 매우 중요하다.

실제시도가 전적으로 관찰가능한 현상만은 아니라고 한다면, 실제적 시도와 인식되어진 시도사이의 일치(N sbett and Val ins 1972) 는 인과관계를 자의적으로 잘못 설정하거나(예: "나는 교재가 너무 어려워서라기 보다는 노력을 하지 않아 시험에 불합격했다" ) 노력 강도에 대해 지각이나 인출상 보상적인 편향을 가짐으로써 단절되기가 쉽다(N sbett and Ross 1980)

2번의 기간에서 TT모형공식에 있어서는 제시된 영향경로 6 개중 4 개가 유의적이었다. 또한 2개의 추가적인 경로가 두 기간중 한번이 유의했지만, 4 개의 TPB모형경로 중 하나만이 유의했다.

좀더 자세히 보자면, $\Pi$ 모형에서 신념과 가치평가의 곱으로 이루어진 시도에 대한 태도중 성공과 과정에 관련된 경로가 완전히 증명되었다. 즉 성공과 과정에 대한 태도는 각각 신념과 가치평가로 이루어진 항에 의해 결정되었다. 더 나아가서, 성공에 대한 태도와 성공기대치로 이루어진 항목과 과정에 대한 태도 항목은 둘 다 시도에 유의한 예측치였다. 하지만 실패관련항목들은 양기간 동안 기대대로 작용하지 못했다. $A_{f} E_{f}$ 는 $A_{t}$ 에 기여하지 못했을 뿐 아니라, $A_{f}$ 자신은 $\sum$ be와도 연관되지 못했다.

$\mathrm{TPB}$ 모형의 결과치는 전반적으로 모호할 뿐만 아니라 설득력이 약하다. 즉, $\mathrm{A}_{\mathrm{s}} \mathrm{E}_{\mathrm{s}}$ 는 $\mathrm{A}_{\mathrm{f}} \mathrm{E}_{\mathrm{f}}$ 와 마찬가지로 두 기간 중 하나에서만 유의한 예측치가되었다. 이 모델에서 명확한 발견은 오직 $A_{s}$ 가 $\Sigma$ be에 의해 결정된다는 사실이었다.

비록 TT모형에 있어 시도에 대한 태도 개념화가 TPB모형보다 더 설득력이 있었지만 $\mathrm{A}_{\mathrm{f}}$ 와 $\mathrm{E}_{\mathrm{f}}$ 항목의 비효과성은 전체연구에서 만족스럽지 못한 발견이었다. 아마도 실패에 대한 고려가 $\mathrm{A}_{\mathrm{t}}$ 의 유의한 결정변수가 아닌 것은 체중 감량에 있어 새로운 시도들이 실패를 즉각적으로 보충해 줄 수가 있기 때문이다.

예를 들어서, 누군가가 어느 주 동안 체중감량에 실패했다면 그는 다음 주에 다시 시도할 수가 있다. 하지만 한번 실패는 최종적인 행위나 결과(예: 대부를 받지 못한 사업가는 다음주에 파산할 것이다), 또는 또 다른 시도를 하기까지는 오랜 시간이 소요되는 행위나 결과 (고시에 실패한 학생은 다음해가 되어야 재응시를 할 수 있다)에 있어서는 실패가 전반적인 $\mathrm{A}_{\mathrm{t}}$ 에 유의한 결정변수가 될 수가 있을 것이다.

우리는 또한 새로운 기술채택에 대한 인식된 위험이 증가할수록 실패결과에 대한 태도는 좀더 의미를 가질 수 있을 것이라고 예상할 수 있다. 하지만 개인별 차이점은 이러한 영향을 완화시킬 수가 있다. 특히 성취동기 부여에 있어 차이점이 그렇다Atki nson 1964). 높은 성공동기를 가진 사람은 실패를 회피하려는 사람들보다 실패와 관련된 결과를 처리하지 않거나 또는 그 결정들을 중요하게 여기지 않을 것이다. 비록 실패에 대한고려가 체중감량 상황에 있어 상반된 결과를 보였지만 실험대상자들은 명확하게 성공과 실패에 
대한 기대치를 형성했다: (첫번째 $r E_{s} E_{f}=-.45$, 두번째 $r E_{s} E_{f}=-.40$ ).

우리가 조사한 이 모형의 가장 참신한 특징은 아마도 의도형성과 실제적인 표적행위나 결과수행 사이에 여러 단계들을 고려하고 있다는 사실이다. 많은 행위들은 의사결정과 행동 단계사이에 시간적인 격차가 있다. 사실상 종종 최종행위를 위해서 중간결정과 중간행위는 필요하다(예: 쇼핑나들이를 준비하는 것; 비교쇼핑). 우리는 수단적 행동의 역할이 시도를 모형화함으로써 이해될 수 있다는 사실을 발견했다.

모든 행동결정이 실현되지 않고 모든 시도노력이 성공적이지 않기 때문에, 만약 우리가 소비행동을 완전히 설명하려한다면(Bagozzi 1992) 의사결정/의도형성과 행위/결과달성간의 과정들을 모형화하는 것이 중요하다. 이성적 행동이론은 그러한 중간 과정에 대한 제시가 없기 때문에 이러한 점이 특히 부족하다. 동시에 중간과정들을 명확히 규정하고 조작화하는 데 있어 여기 제시한 것 이상의 더 많은 연구가 필요할 것이다. 


\section{참 고 문 헌}

이학식, 김영(1998), “태도-행동 관계에 대한 조정변수들의 역할- 대선 투표행동 체계에서," 소비자학연구, 9권 2호, 37-64.

임종원, 김재일, 홍성태, 이유재(1999), 소비자행동론, 제2판, 경문사.

Aj zen, I cek (1985), "From Intenti ons to Actions: A Theory of Pl anned Behavi or, " in J.

Kuhl and J. Beckmann eds., Acti on Control: From Cogni ti on to Behavi or, New

York: Spri nger-Verl ag, 11- 39.

Aj zen, I cek ( 1991), "The Theory of Pl anned Behavi or: Some Unr esol ved I ssues, "

Organi zati onal Behavi or and Human Deci si on Processes, 50, 179- 211.

Aj zen, I cek and Mart i n Fi shbei n (1980), Under st andi ng Attitudes and Predi cti ng Soci al

Behavi or, Engl ewood Cliffs, N: Prenti ce- Hall .

Aj zen, I cek and T.J. Madden (1986), "Predi cti on of Goal - di rect ed Behavi or: At ti tudes, Int enti ons, and Percei ved Behavi or al Control, " Journal of Experi mental Social Psychol ogy, 22, 453-474.

Bagozzi, Ri chard P. (1992), "The Self-Regul at $i$ on of Attitudes, Int ent $i$ ons, and Behavi or, " Soci al Psychol ogy Quarterly, 55, 178204.

Bagozzi, Ri chard P. (1993), "On the Negl ect of Vol iti on in Consuner Research: A Critique and Proposal ," Psychol ogy and Narketing, 10, 215237.

Bagozzi, Ri chard P., Hans Baungartner, and Ri k Pi eter s (1998), "Goal- Di r ect ed Enot i ons, " Cogniti on and Enoti on, 12(1), 1- 26.

Bagozzi, Ri chard P., Hans Baungartner, and Youj ae Yi (1989), "An I nvesti gati on i nto the Rol e of Intentions as Medi at or s of the Attitude-Behavi or Rel at i onshi p, " Journal of Economic Psychol ogy, 10(1), 3562.

Bagozzi, Ri chard P., Hans Baungartner, and Youj ae Yi (1992), "Apprai sal Processes in the Enact ment of I ntenti ons to Use Coupons, " Psychol ogy and Narketing, 9, 469486.

Bagozzi, Ri chard P., Hans Baungart ner, and Youj ae Yi (1992), "St ate- vs. Acti onOri ent at $i$ on and the Theory of Reasoned Act i on: An Appl i cat i on to Coupon Usage, " Journal of Consumer Research, 18, 505-518.

Bagozzi, Ri chard P. and Ut pal Dhol aki a (2000), "Goal-Setting and Goal-Striving in Consumer Behavi or, " unpubl i shed working paper. 
Bagozzi, Ri chard P. and El i zabeth A. Edward (1998), "Goal-Setting and Goal Pur suit in the Regul at i on of Body Wei ght, " Psychol ogy and Heal th, 13, 593- 621.

Bagozzi, Ri chard P. and Susan K K mmel (1995), "A Compari son of Leadi ng Theor i es for the Predicti on of Goal-Directed Behavi or, "British Journal of Soci al

Psychol ogy, 34, 437- 461.

Bagozzi, Ri chard P. and Paul R. War shaw (1990), "Tryi ng to Consume, " Journal of Consumer Resear ch, 17, 127- 140.

Bagozzi, Ri chard P. and Youj ae Yi (1989), "The Degree of I nt enti on For mati on as a Noder at or of the Attitude- Behavi or Rel at i onshi p, " Soci al Psychol ogy Quarterly, 52, 266- 279.

Bagozzi, Ri chard P., Youj ae Yi, and Hans Baungart ner (1990), "The Level of Effort Requi red for Behavi or as a Moder at or of the Attitude- Behavi or Rel at i on, " Eur opean Journal of Soci al Psychol ogy, 20, 45-59.

Bandur a, Al bert (1997), Self-Effi cacy: The Exerci se of Control. New York: Fr eeman.

Bargh, J.A. (1990), "Aut o- not i ves: Preconsci ous Det er minants of Thought and Behavi or, " in Handbook of Mot i vati on and Cogniti on: Foundati ons of Soci al Behavi or, Vol.2, E.T. H ggi ns and R.M Sorrenti no, eds. New York: Guil ford, 93130.

Bargh, J. A. and Barndol I ar (1996), "Aut omat i city in Acti on: The Unconsci ous as Reposit ory of Chroni c Goal s and Notives," in The Psychol ogy of Acti on: Li nki ng Cogniti on and Motivati on to Behavi or, P.M Gol I witzer and J.A. Bargh, eds. New York: Gui I ford, 457- 481.

Bar sal ou, L.W (1991), "Deri vi ng Cat egor i es to Achi eve Goal s, " in The Psychol ogy of Learni ng and Notivation, Vol. 27, G.H. Bower, ed. New York: Academic Press, 164.

Bent l er, Peter M and G Speckart (1979), "Mdel s of At ti tude- Behavi or Rel at i ons, " Psychol ogi cal Revi ew, 86(5), 452464.

Carver, C. S. and MF. Schei er (1996), On the Sel f-Regul at i on of Behavi or, New York: Cantor i dge Uni versi ty Press.

Dweck, C. S. (1991), "Sel f-Theori es and Goal s: Thei $r$ Rol e in Not i vati on, Per sonal ity, and Devel opment, " in Nebraska Symposi um on Mti i vati on, Vol. 38, R. Di enst bi er, ed. Li ncol n: Uni versity of Nebraska Press, 199- 255.

Gol I wi tzer, Peter M and V. Brandst at ter (1997), "I mpl enent at $\mathrm{i}$ on I nt ent $\mathrm{i}$ ons and Effective Goal Pursuit," Journal of Per sonal ity and Soci al Psychol ogy, 73, 
186- 199.

Huff man, C., S. Rat neshwar, and D. G. Mck (1997), "Towar d a Framework of Goal Det er min nat i on i n Consumer Behavi or , " unpubl i shed manuscri pt, The Wart on School, The Uni versity of Pennsyl vani a.

Jor eskog, Karl and Dag Sor bom (1993), LI SREL8 User's Ref er ence Gui de. Chi cago: Sci ent i f i c Sof tware I nt er nat i onal .

Kuhl, Jul i us and J. Beckman (1994), Vol i ti on and Per sonal i ty. Tor ont o: Hogr ef e. Lawson, R. (1997), "Consumer Deci si on Naki ng wi thi n a Goal- Dri ven Fr anework, " Psychol ogy and Narket ing, 14(August), 427- 449.

Locke, E. A. and G. P. Latham (1990), A Theory of Goal Setting and Task Performance. Engl ewood Cliffs, N: Prentice- Hall.

Nathur, Ani I (1998), "Examining Trying as a Medi at or and Control as a Noder at or of I nt ent i on- Behavi or Rel at i onshi p, " Psychol ogy and Marketi ng, 15, 241- 259.

Or bel I, S., S. Hodgki ns, and P. Sheer an (1997), "I mpl enent at i on I nt ent i ons and the Theory of Pl anned Behavi or, " Per sonal ity and Soci al Psychol ogy Bul I et i n, 23, 945- 954.

Parker, Di anne, Ant ony S. R. Nanstead, and St ephen G Stradling (1995), "Ext endi ng the Theory of Pl anned Behavi or: The Role of Personal Norm " British Journal of Soci al Psychol ogy, 34, 127-137.

Petty, R.E. and J. Caci oppo (1986), Communi cati on and Per suasi on: Central and

Per i pher al Rout es to Atti tude Change. New York: Spri nger- Verl ag.

Pi et er s, Ri k, Hans Baungart ner, D. Al I en (1995), "A Means- End Chai n Approach to Consumer, " Internati onal Journal of Research in Market ing, 12, 227- 244.

Rat neshwar, S., C. Pechmann and A. D. Shocker (1996), "Goal- Der i ved Cat egor i es and the Ant ecedent s of Acr oss- Cat egory Consi der at i on, " Journal of Consumer Research, 23( Decenber ), 240250.

Sheppard, B., J. Hartwi ck, and P. R. War shaw (1988), "The Theory of Reasoned Acti on: A Net a- Anal ysi s of Past Research and Recommendati ons for Nodi fi cati on and Fut ure Resear ch, " Journal of Consumer Resear ch, 15, 325-343.

War shaw, Paul and Fred davi s (1985), "Di sentangl ing Behavi or al I nt ent i on and Behavi or al Expect at $\mathrm{i}$ on, " Journal of Exper i ment al Soci al Psychol ogy, 21( Nay), 213228.

Wtt enbraker, J. , B. L. Gi bbs, and L.R. Kahl e (1983), "Seat Bel t Attitudes, Habi ts, and Behavi or: An Adapt i ve Anendment to the Fi shbei n Model, " Journal of Appl i ed 
Soci al Psychol ogy, 13(5), 406421.

Yi, Youj ae (1989), "An I nvesti gati on of the Structure of Expectancy-Val ue Attitude and I t s I mpl i cati ons, " I nt ernati onal Journal of Research in Narketing,

6( Decenmer) , 71- 83.

Yi, Youj ae \& Ken Gray (1992), "New Per specti ves in Attitude Research," Advances in

Consumer Resear ch, 19, 319322.

Yi, Youjae \& Ken Gray(1996), "Revisiting Attribute Diagnosticity in the Context of Product Typicality," Psychology and Marketing, 13(6), 605-632. 